\title{
CORRECTION OF MODEL DEFORMATION EFFECTS FOR A SUPERCRITICAL WING IN TRANSONIC WIND TUNNEL
}

\author{
Dawei Liu, Xin Xu, Qiang Li, Xin Peng, Dehua Chen
}

Original scientific paper

This paper presents a method to correct test model deformation effects due to aerodynamic loads in transonic wind tunnel. Deformation for a supercritical wing test model was measured under variation of dynamic pressure in the European Transonic Wind tunnel (ETW) using the Stereo Pattern Tracking (SPT) system. Deformed model mesh was generated by the structure grids deformation technology developed in this paper, and numerical results of rigid and deformed models were achieved based on the RANS solver. Then, correction of model deformation was obtained by subtracting the computational longitudinal aerodynamic coefficients of original model from those of deformed one. Results indicated that a good correlation of experimental and numerical results of deformed model was achieved, validating the reliability of numerical method developed to simulate model deformation. It is also suggested that the method developed in this paper could be used to correct test model deformation for original wind tunnel data.

Keywords: correlation; ETW; SPT; structure grids deformation; test model deformation

Ispravak učinaka deformacije modela za superkritično krilo u transoničkom vjetrenom tunelu

Izvorni znanstveni članak

Ovaj rad predstavlja metodu kojom se ispravljaju učinci deformacije ispitnog modela zbog aerodinamičkih opterećenja u transoničkom vjetrenom tunelu. Deformacija za superkritični ispitni model krila mjerena je pod utjecajem dinamičkog tlaka u European Transonic Wind tunelu (ETW) pomoću Stereo Pattern Tracking (SPT) sustava (sustava za stereo praćenje uzoraka). Deformirana mreža modela stvorena je tehnologijom deformacije strukturnih rešetaka razvijenom u ovom radu, a numerički rezultati krutih i deformiranih modela postignuti su na osnovi RANS-a (Reynolds-averaged Navier-Stokes solver). Zatim je ispravljena deformacija modela dobivena oduzimanjem računalnih uzdužnih aerodinamičkih koeficijenata originalnog modela od onih deformiranog. Rezultati su pokazali da je postignuta dobra korelacija eksperimentalnih i numeričkih rezultata deformiranog modela, potvrđujući pouzdanost numeričke metode koja je razvijena kako bi se simulirala deformacija modela. Također se predlaže da se metoda razvijena u ovom radu može upotrijebiti za korekciju deformacije testnog modela za izvorne podatke vjetrenog tunela.

Ključne riječi: deformacija ispitnog modela; deformacija strukturnih rě̌etaka; ETW; korelacija; SPT

\section{Introduction}

At present, wind tunnel tests are still used throughout the design process both as a means of assessing the current level of aircraft performance and in order to calibrate the CFD (Computational Fluid Dynamics) codes being used [1]. To achieve the reliable aerodynamic characteristics of test model, there are some corrections to be performed in wind tunnel such as correction of sting interference, wall interference, model deformation effects and so on [2]. Sting and wall interference correction have been studied for several years and some mature methods are formed in wind tunnels. However, it was difficult to correct the test model deformation due to aerodynamic loads in wind tunnel test several years ago, thus engineers had to use aerodynamic data which was not so accurate in the aircraft design. The deformation effects of low aspect ratio wings may not be so apparent, but it is a crutial problem for supercritical wing in wind tunnel test. First, supercritical wings are widely used in civil transport aircrafts for high aerodynamic efficiency and the ability to predict the aerodynamic qualities of an aircraft design accurately is of paramount importance [1]. Then, the Reynolds number effects of supercritical wing are very complex and should be investigated by the variation of total pressure even though experiment is conducted in cryogenic wind tunnel. Pseudo Reynolds number effects will be obtained if model deformation is not corrected, because the model deformation varies with the different total pressure. Moreover, the aeroelastic effects of supercritical wings are severe, which are usually corrected by the tests of rigid model and elastic model in wind tunnel. Test model deformation should be corrected to get the clean aerodynamic data of rigid model. Finally, a better correlation of experimental and computational results also needs the correction of test model deformation [3].

In the past few years, the deformation of test model could be measured while experiment was performed with the development of optical measurement technology $[4 \div 7]$. Many researchers were devoted to the development of optical measurement of model deformation. In [8], three optical methods for measuring model deformation were compared by Burner A W and Fleming G A and characteristics of different methods were achieved. Liu T and Cattafesta investigated the application of photogrammetry in wind tunnel test [9]. In [10], a kind of optical measurement device based on three line array CCDs-Optotrak system and the measurement technology by the system were investigated by SONG Jin for low speed wind tunnel. Deformation with different velocities was obtained by installing Markers on several airfoils and the attitude angle of test model was also measured. SUN Yan and DENG Xiaogang studied the Markers influence on aerodynamic characteristics in video model deformation experiments for an airfoil RAE2822 test model [11]. Results of several thicknesses and position for Markers on test model were compared in their research. Nowadays, the optical measurement of model deformation has become a conventional technology in advanced wind tunnels such as ETW [12, 13] and the National Transonic Facility (NTF) [14].

Since the CFD method is now playing a more and more important role in the aircraft design and many other 
engineering problems $[15 \div 21]$, it is also feasible to correct test model deformation effects by numerical method. In most cases, CFD results are not so accurate in absolute values, but the incremental values are usually reliable. Deformed model can be restructured with measured deformation of test model, and both of the aerodynamic characteristics of original and deformed models could be achieved through CFD method. Correction of model deformation could be obtained by subtracting results of original model from those of deformed one. The idea of performing correction of test model deformation is not complex, but few related reports have been published especially for supercritical wings. Researchers of wind tunnels are usually paying more attention to measuring the test model deformation, while an aircraft designer focuses on the aeroelastic effects. SUN Yan and ZHANG Zhengyu investigated the influence on aerodynamic characteristics by wind tunnel model deformation based on the numerical method [22]. In their study, the model deformation is based on the mixed grids deformation technology which may induce the computational errors due to variation of grids topology and boundary layer mesh density. Moreover, the reliability of computational method considering model deformation has not been validated yet by experimental results and the correction data was not presented.

In this paper, the deformations of a supercritical wing model were measured by SPT system in ETW at different test conditions, including normal dynamic pressure for low Reynolds number and high dynamic pressure for flight Reynolds number. With the measured deformation, deformed model was restructured and the mesh was regenerated based on the structure grids deformation technology developed in this research. The computational errors due to variation of mesh structure could be reduced by keeping grids topology and boundary layer mesh density of deformed model the same as those of original one. Experimental results are compared with computational results of deformed model, validating the reliability of numerical method simulating model deformation. Correction data of test model deformation are provided for the supercritical wing based on the numerical results of original and deformed model.

\section{Model and test facilities \\ 2.1 Model}

Test model is a typical supercritical wing with a fuselage made from maraging steel for cryogenic conditions [3]. The wing span of test model is $1.56 \mathrm{~m}$ and mean aerodynamic chord is $0.202 \mathrm{~m}$. Fixed transition is located at the $7 \%$ local chord length away from the leading edge for both upper and lower wing surface while the Reynolds number is less than 15 million. Fixed transition will be removed for the Reynolds number above 15 million. The test model was installed in ETW test section by the $\mathrm{Z}$ sting support as can be seen in Fig. 1 .

Markers for the SPT system were attached to the port wing lower surface as can be seen from Fig. 2. The markers were applied on the leading and trailing edge areas with increasing intensity towards the outboard region. A total 40 markers were applied. The standard marker definition was:
(1) Letraset type markers;

(2) Black center, diameter $6 \mathrm{~mm}$, on a white back ground diameter $16 \mathrm{~mm}$;

(3) Thickness: $4 \mu \mathrm{m}$ per layer.

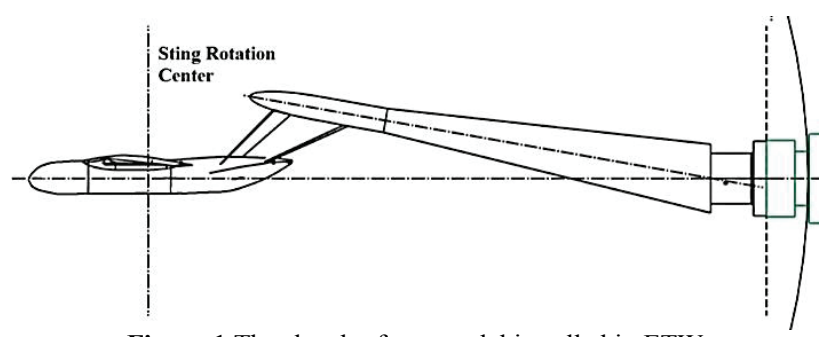

Figure 1 The sketch of test model installed in ETW

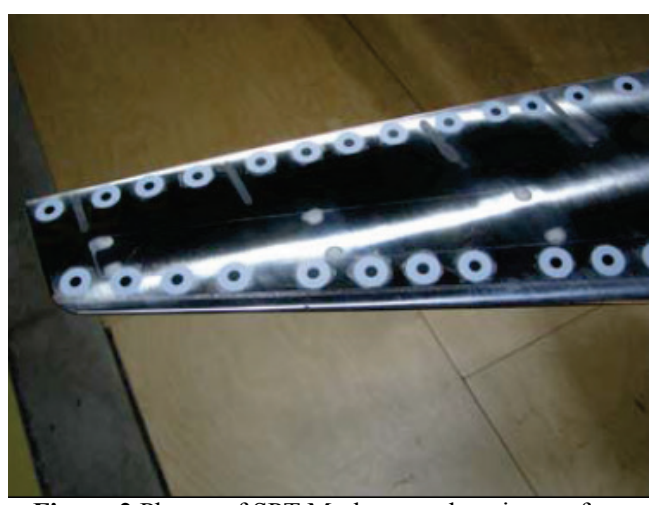

Figure 2 Photos of SPT Markers on the wing surface

The location of typical SPT Markers is presented in Tab. 1 and only the deformations of these wing sections are offered.

Table 1 The location of typical SPT Markers

\begin{tabular}{|c|c|c|c|c|c|}
\hline No. & 1 & 2 & 3 & 4 & 5 \\
\hline$Z$ & 0.883 & 0.1735 & 0.2461 & 0.3412 & 0.4214 \\
\hline$\eta$ & $11.3 \%$ & $22.2 \%$ & $31.5 \%$ & $43.7 \%$ & $54.0 \%$ \\
\hline No. & 6 & 7 & 8 & 9 & 10 \\
\hline$Z$ & 0.4917 & 0.5647 & 0.6719 & 0.754 & 0.7804 \\
\hline$\eta$ & $63.0 \%$ & $72.4 \%$ & $86.1 \%$ & $96.6 \%$ & $100.0 \%$ \\
\hline
\end{tabular}

\subsection{Wind tunnel}

Experiment was conducted in the ETW facility, which is high Reynolds number transonic wind tunnel using nitrogen as the test gas. High Reynolds numbers are achieved under the combined effects of low temperature and moderately high pressures. As one can see in Fig. 3, it has a closed aerodynamic circuit with a Mach number range from $M=0.15$ to 1.3 . The test section is $2.00 \mathrm{~m}$ high, $2.40 \mathrm{~m}$ wide and $9.00 \mathrm{~m}$ long [3].

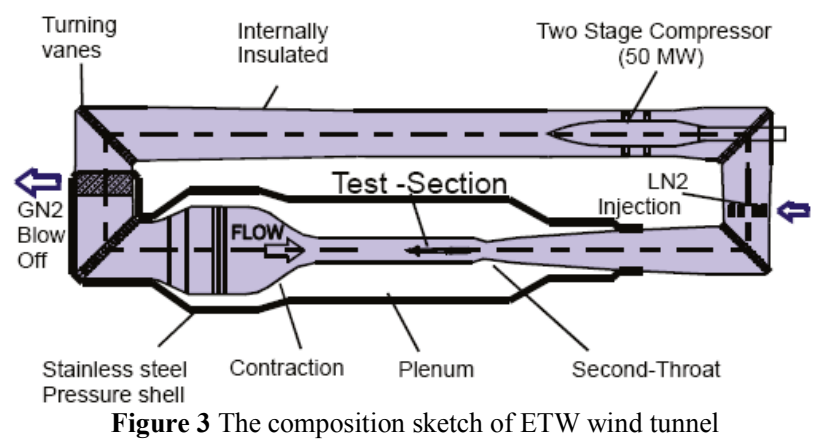

Figure 3 The composition sketch of ETW wind tunnel 
Tests in this paper were performed at Mach numbers in the range of $M=0.4$ to 0.86 and at Reynolds numbers between 2.3 and 35 million. Pressure levels from 124 to $340 \mathrm{kPa}$ were achieved at tunnel temperatures between 300 and $114 \mathrm{~K}$.

\subsection{Model deformation measurement system}

The ETW SPT system is widely used in the measurement of model deformation. Fig. 4 displays the SPT Markers applied on the wing and horizontal tail of a test model with twin support system [12].

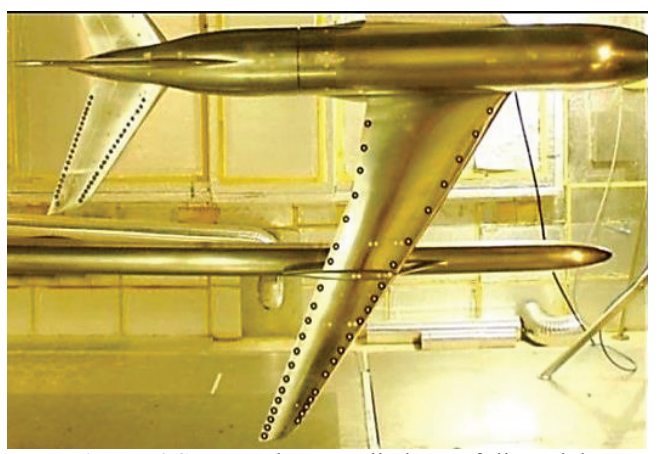

Figure 4 SPT Markers applied on a full model

In this study, the SPT system was installed in the top wall of model cart and the principle of the system is to track up 40 markers placed on the lower wing surface during a pause polar with two cameras (each having its own viewing angle). At each incidence step, the system records several images which are processed to indicate the 3-D displacement of each marker. Based on wind-off reference measurements over the entire incidence range of the model, the system can identify the displacement between loaded and unloaded conditions, which then can be finally transformed into wing twist and bending information. For the illumination of the SPT markers LED lights were installed at several positions in test section.

Prior to the test, a calibration of the measurement volume must take place with a calibration frame. This frame is fitted with about 30 bulbs, for which the coordinates are known very accurately. The bulbs are sequentially switched on, automatically identified by the SPT system and linked to their 3-D coordinates.

The SPT tests were undertaken in the pause model of operation with up to 15 stabilized points per polar. Images were acquired with $5 \mathrm{~Hz}$ for 6-8 seconds per condition to provide sufficient data to meet the anticipated accuracy.

Model deformation measurements were performed for selected test conditions.

\section{Computational method \\ 3.1 Governing equations}

Flow over the test model is governed by three dimensional Navier-Stokes equations and the integral form for an arbitrary control volume $\Omega$ is as follows:

$$
\frac{\partial}{\partial t} \iiint_{\Omega} U \mathrm{~d} V+\iint_{\partial \Omega} F \cdot n \mathrm{~d} S=0
$$

Among them, $\partial \Omega$ represents the control volume boundary, $U$ represents the state variables of control volume, $S$ represents the surface of control volume, $\boldsymbol{n}$ represents the normal unit vector, $\boldsymbol{F}$ represents the matrix of all the $\mathrm{N}-\mathrm{S}$ equations items except time ones.

$$
\boldsymbol{F}=\left[\begin{array}{l}
E_{\mathrm{c}}-\frac{1}{R e} E_{\mathrm{v}} \\
F_{\mathrm{c}}-\frac{1}{R e} F_{\mathrm{v}} \\
G_{\mathrm{c}}-\frac{1}{R e} G_{\mathrm{v}}
\end{array}\right]
$$

$E_{\mathrm{c}}, F_{\mathrm{c}}, G_{\mathrm{c}}$ represent inviscid flux, while $E_{\mathrm{v}}, F_{\mathrm{v}}, G_{\mathrm{v}}$ represent viscid flux in Eq. (2).

The N-S equations are discretized with the finite volume method and the computational domain is divided into many small control volumes. For the No. $i$ control volume, the equations are described as follows:

$V_{i} \frac{\partial U_{i}}{\partial t}=-\boldsymbol{R}_{i}$

where $\boldsymbol{U}_{\boldsymbol{i}}$ represents the mean value of the state variables of control volume No. $i, \boldsymbol{R}_{i}$ represents the residual of the total flux vector going through the surface of the control volume, $V_{i}$ represents the volume of No. $i$.

\subsection{Governing equations solution method}

The three dimensional Reynolds averaged NavierStokes flow solver has been developed and the convective flux calculation follows Osher's approximate Riemann solver with a MUSCL scheme for higher order accuracy. An implicit method is used for the time discretization and the turbulence model is $\mathrm{K} \omega$-SST.

Time iterative method was applied in this calculation program to solve steady-state problem. The equation for the $n^{\text {th }}$ time interval is as follows,

$\frac{U^{n+1}-U^{n}}{\Delta t}=-R\left(U^{n}\right)$

That is,

$$
U^{n+1}=U^{n}-\Delta t R\left(U^{n}\right)
$$

The symbol $t$ in Eq. (4) and (5) represents the time.

\subsection{CFD solver verification}

Fig. 5 illustrates the comparison of experimental and computational results by using the CFD solver developed in this paper for a stand model [3]. As can be seen, the slopes of lift coefficient $\left(C_{L}\right)$ and drag coefficient $\left(C_{D}\right)$ curves are nearly the same for both results, also the break points are at the same incidence angles. The shape of pitch moment coefficient $\left(C_{m}\right)$ curves is similar and the numerical result is a little larger due to the uncorrected sting support interferences [3]. As a whole, the 
experimental results compare well with computational results, proving the CFD solver reliable.

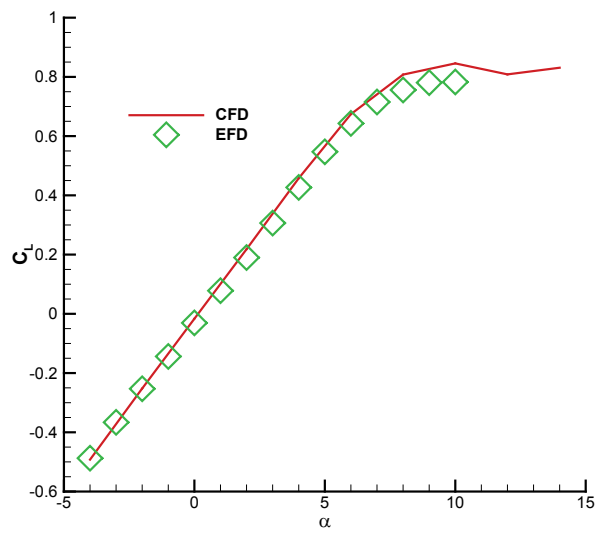

(a) $C_{L} \sim \alpha$

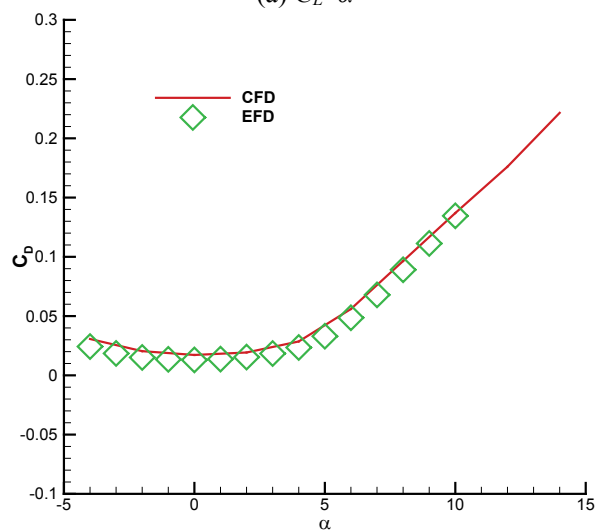

(b) $C_{D} \sim \alpha$

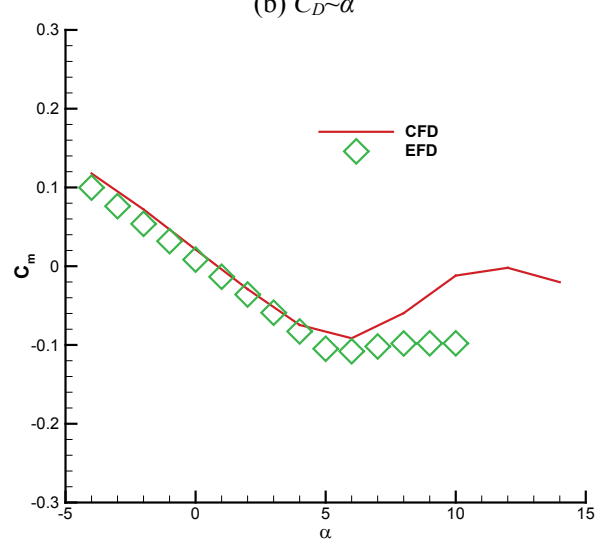

(c) $C_{m} \sim \alpha$

Figure 5 CFD solver validation by experimental results of aerodynamic coefficients for Ty 154 model $(M=0.8)$

\subsection{Grids deformation technology}

Experimental data obtained from wind tunnel were the aerodynamic results of deformed test model, and model deformation correction should be performed based on the numerical method. Therefore, it has great significance to regenerate the deformed mesh swiftly based on the original grids. During the process of mesh regeneration, the outer boundary grids keep fixed and grids on the wall move with the wall, while the movement of interior area grid points will be computed in accordance with a mathematical model. There are three kinds of grids deformation technology, including algebraic method, iterative method and analytical method. Both the algebraic method and analytical method are only suitable for the small deformation, while the iterative method is usually used to solve the large deformation problem, which needs much more computational resources.

Since test model deformation in wind tunnel is usually small, with the consideration of varieties of model deformation at different attack angles, the algebraic grids deformation method is applied to generate new mesh based on the spring model. The advantage of this method is to keep deformed mesh and original one the same as far as possible, including the topology of grids and density of boundary layer mesh, thus reducing the computational errors due to mesh deformation.

For this method, the girds on the wall first move to deformed position, then the displacement of deformed wall and original wall is transferred to outside as a spring. During the process, the moving displacement of grid point will be calculated as the ratio determined by the location of grid point, which guarantees the mesh of outside boundary does not vary. The specific operating steps to regenerate deformed mesh are as follows.

\subsubsection{Generation of original mesh}

The computational grids consisting of 64 blocks were generated by commercial software with a grid number about $1.0 \times 10^{7}$, and grid distribution on wall surface meets $y+=1$. Influence of grids magnitude was investigated in [3]. Fig. 6 shows the topology of computational grids and Fig. 7 displays the grids distribution near the wall.

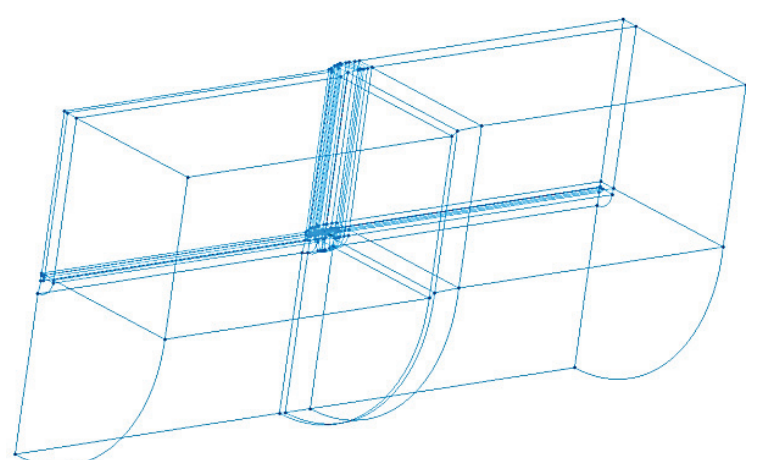

Figure 6 Grids topology of the supercritical wing

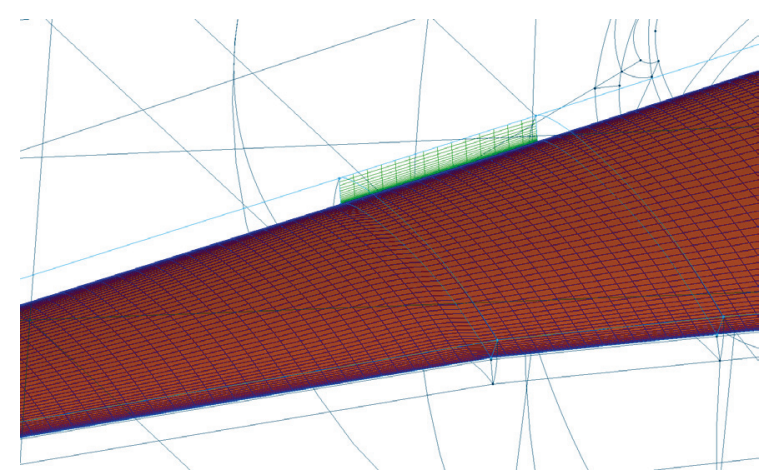

Figure 7 Grids points distribution near the wing

\subsubsection{Selection of control slice}

The supercritical wing deformation caused by aerodynamic loads during wind tunnel test mainly includes the bending and twist deformation, and deformation for each wing section is different. Some wing sections are 
selected as the control slices of model deformation, and the deformation between the adjacent two slices could be obtained through linear interpolated. In this paper, those wing sections where SPT Markers were located are selected as the control slices. Fig. 8 shows the sketch of control slices.

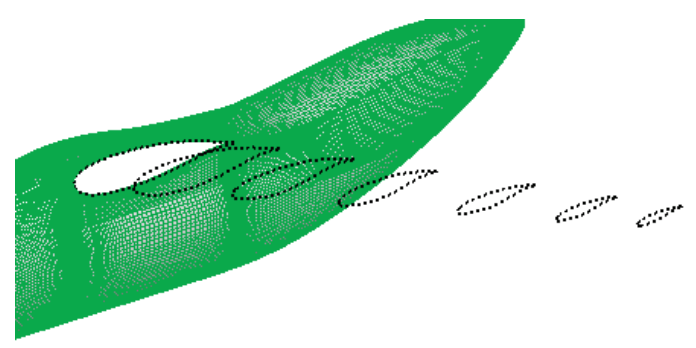

Figure 8 Sketch of control slices of the test model

\subsubsection{Movement of the control slice}

The control slice deformation was obtained by SPT system and the bending and twist deformation are overlaid together, thus the new position of control slice could be determined. Fig. 9 plots the displacement of control slices.

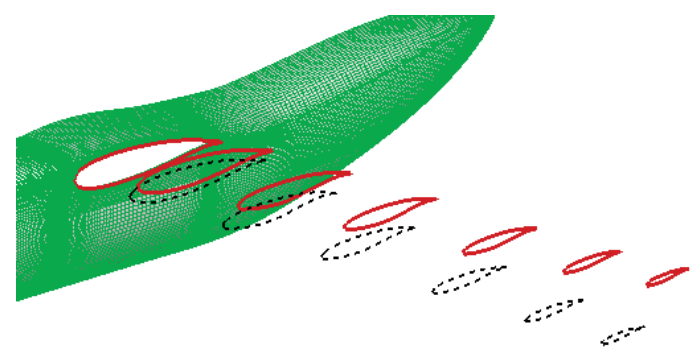

Figure 9 Sketch of control slices displacement

\subsubsection{Generation of new mesh on the wall}

As stated before, the displacement of grid points between two adjacent control slices could be obtained through linear interpolation and the new meshes on deformed wall could be generated in such a way (seen in Fig. 10).

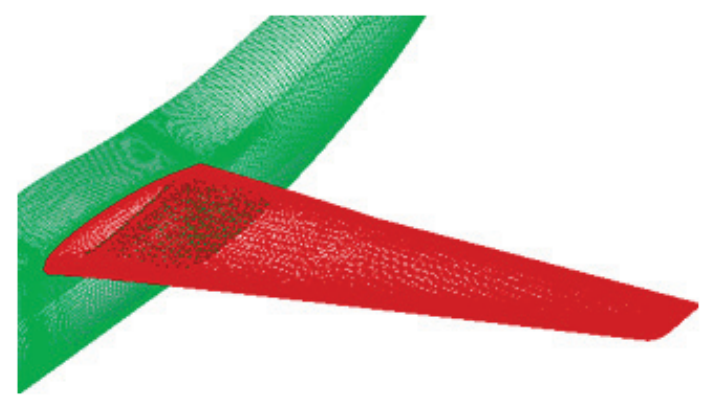

Figure 10 New meshes on the deformed wall

\subsubsection{Generation of space grid}

Space grids between the deformed wall and outside boundary will be updated as a principle. The outside boundary is not the far field computational boundary, but the outermost layer of the boundary layer mesh if wall deformation is small. Therefore, the updating of space grids mainly focuses on the boundary layer mesh. However, if wall deformation is large, the outside boundary will be defined as the outmost layer of the middle layer mesh near boundary layer. Thus, the updating of space grids focuses on the boundary layer and middle layer.

Specific algorithm of marching deformation from the wall is demonstrated as the following. The $x$ direction is taken as the example and the $y$ and $z$ directions are similar to $x$ direction.

$$
\begin{aligned}
& x_{j}^{\text {new }}=x_{j}^{\text {old }}+[1-\operatorname{arc}(j)]\left(x_{\text {surface }}^{\text {new }}-x_{\text {surface }}^{\text {old }}\right) \\
& \operatorname{arc}(j)=\sum_{l=2}^{j} L_{l} / \sum_{l=2}^{j_{n}} L_{l} \\
& L_{l}=\sqrt{\left(x_{l}-x_{l-1}\right)^{2}+\left(y_{l}-y_{l-1}\right)^{2}+\left(z_{l}-z_{l-1}\right)^{2}}
\end{aligned}
$$

where,

$x_{\text {surface }}^{\text {old }}$ represents the grid point on the original wall.

$x_{\text {surface }}^{\text {new }}$ represents the grid point deformed wall.

$x_{j}^{\text {old }}$ represents the grid point of the original space.

$x_{j}^{\text {new }}$ represents the grid point of the deformed space.

Fig. 11 illustrates the original and deformed grids on the wall. The pure bending, pure twist and mixed deformation are presented respectively.

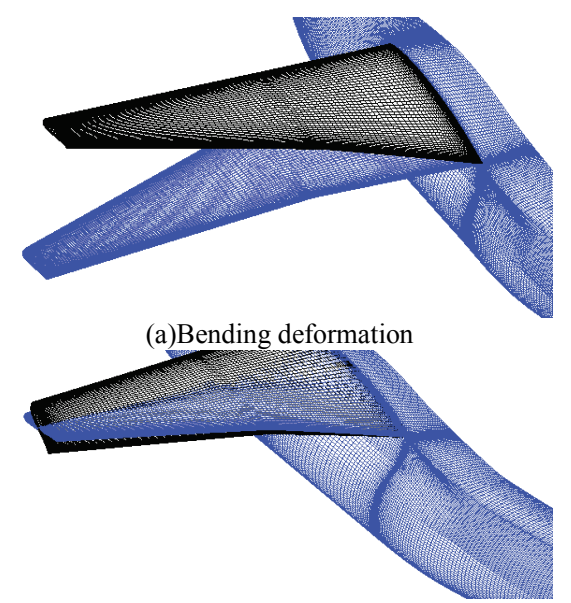

(b) Twist deformation

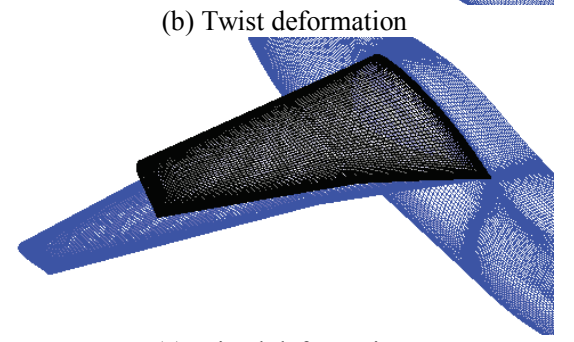

(c) Mixed deformation

Figure 11 Different kinds of mesh deformation on the wing

\section{Results and discussion \\ 4.1 Measured model deformation results}

Measured model deformation of different incidence angles is plotted in Fig. 12 at low Reynolds number condition of $M=0.76, Q=34 \mathrm{kPa}$ and $R e=3.3 \times 10^{6}$. As can be seen from Fig. 12(a), the bending deformation of inboard wing is smaller than outboard wing at a constant incidence angle. With increment of incidence angle 
$\left(\alpha>0^{\circ}\right)$, the bending deformation gets larger as a whole. For minus attack angles, the bending deformation increases with the absolute value of angles. The largest bending deformation is about $5.8 \mathrm{~mm}$ at the wing tip $\left(\alpha=6.99^{\circ}\right)$, meaning the deformed wing tip is $5.8 \mathrm{~mm}$ above original wing tip. As shown in Fig. 12(b), variation of twist deformation with attack angles is similar to bending deformation except some specific angles. For example, the twist deformation of $\alpha=2.00^{\circ}$ is smaller than that of $\alpha=0.99^{\circ}$ at the wing tip, which may be caused by test model vibration. The largest twist deformation is about $-0.24^{\circ}$ at the wing tip $\left(\alpha=6.99^{\circ}\right)$, meaning the local incidence angle of deformed wing tip is smaller than that of original one.

In essence, the magnitude of deformation is dependent on aerodynamic loads and wing section location. The higher aerodynamic loads on the wing obviously results in larger deformation. Since the inboard wing section has a larger thickness and chord length than outboard wing section, the structure of inboard wing is stronger than that of outboard wing. The distance from wing section to fuselage is another main factor influencing bending deformation, so the outboard wing bending deformation is larger than inboard one. Twist deformation of wing section is also influenced by local aerodynamic loads. The higher local aerodynamic loads cause larger twist while stronger structure reduces twist deformation. Thus there is a balance between higher aerodynamic loads and stronger structure for inboard wing section. It seems from Fig. 12(b) that the stronger structure prevails, so twist deformation of outboard wing is also larger in whole.

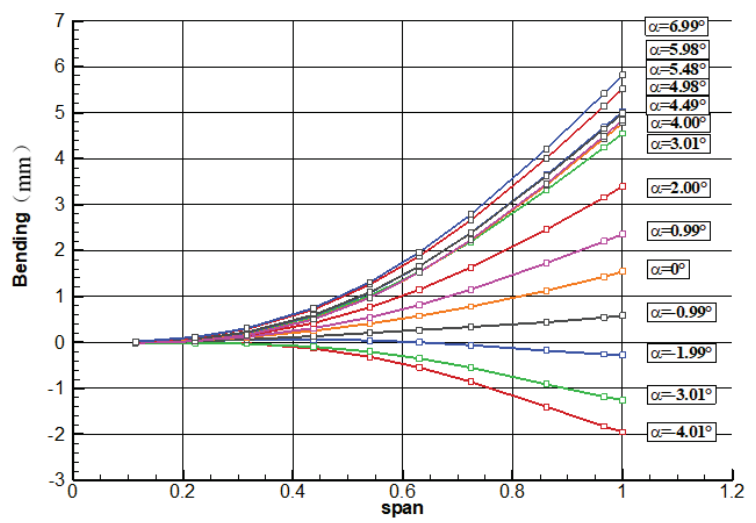

(a) Bending deformation

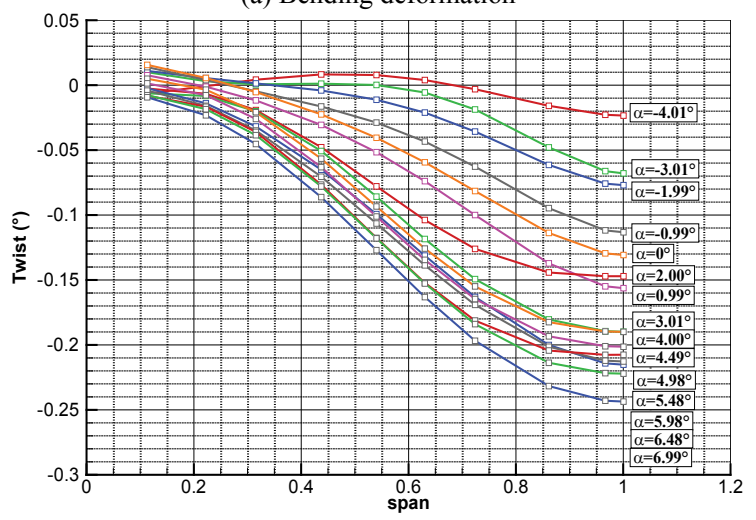

(b) Twist deformation

Figure 12 Variation of test model deformation with incidence angles at $M=0.76, Q=34 \mathrm{kPa}$ and $R e=3.3 \times 10^{6}$
Fig. 13 displays the measured model deformation at flight Reynolds number condition of $M=0.76, Q=92 \mathrm{kPa}$, $R e=3.5 \times 10^{7}$. To achieve the flight Reynolds number $R e=3.5 \times 10^{7}$, the total temperature reached $114 \mathrm{~K}$ and total pressure reached $333 \mathrm{kPa}$. Since the dynamic pressure of flight Reynolds number $(Q=92 \mathrm{kPa})$ is much higher than that of low Reynolds number condition $(Q=34 \mathrm{kPa})$, both of the aerodynamic loads and model deformation are larger as seen from Fig. 12 and Fig. 13. The highest bending deformation is about $15.1 \mathrm{~mm}$ and the largest twist deformation is about $-0.65^{\circ}$ at the wing tip $\left(\alpha=4.02^{\circ}\right)$.

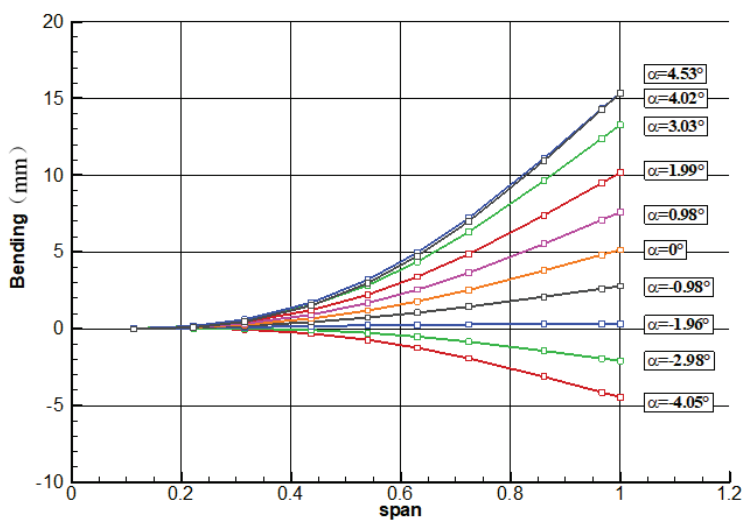

(a) Bending deformation

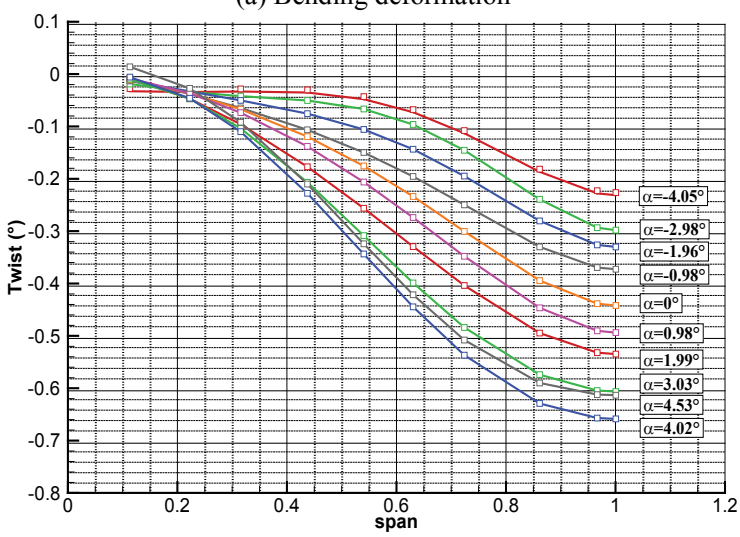

(b) Twist deformation

Figure 13 Variation of test model deformation with incidence angles at $M=0.76, Q=92 \mathrm{kPa}$ and $R e=3.5 \times 10^{7}$

\subsection{Comparisons of experimental and computational results}

Experimental and computational results are compared to validate the reliability of this method [3]. With measured model deformation, deformed mesh of the wing was generated based on the grids deformation technology. Experimental results obtained in ETW wind tunnel include model deformation effects, while there are two kinds of computational results. One is for the original rigid model with no consideration of deformation effects and the other is for the new deformed model restructured by measured deformation.

Typical results are displayed in Fig. 14 at $M=0.76$, $\alpha=2^{\circ}$ and $R e=3.3 \times 10^{6}$. It is obvious that the pressure distributions of experimental results compare well with those of computational result with consideration of model deformation (CFD-deform), while there are apparent differences between experimental results and computational results for original rigid model (CFD-rigid). 
As seen in Fig. 14, the pressure coefficient of CFD-rigid results is lower than CFD-deformed results; the reason of this phenomenon is that deformed model has a minus twist deformation resulting in the decrement of local incidence angle.

Since an excellent correlation between experimental and computational results with consideration of model deformation, the reliability of simulated model deformation effects is reliable.

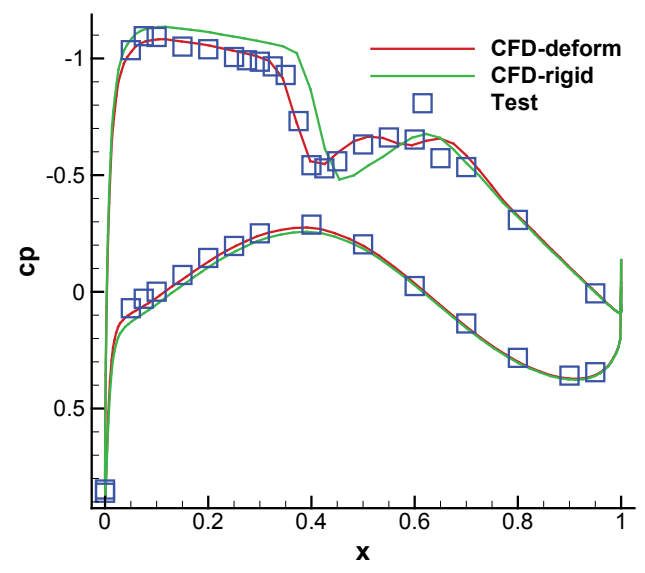

(a) $\eta=72.36 \%$

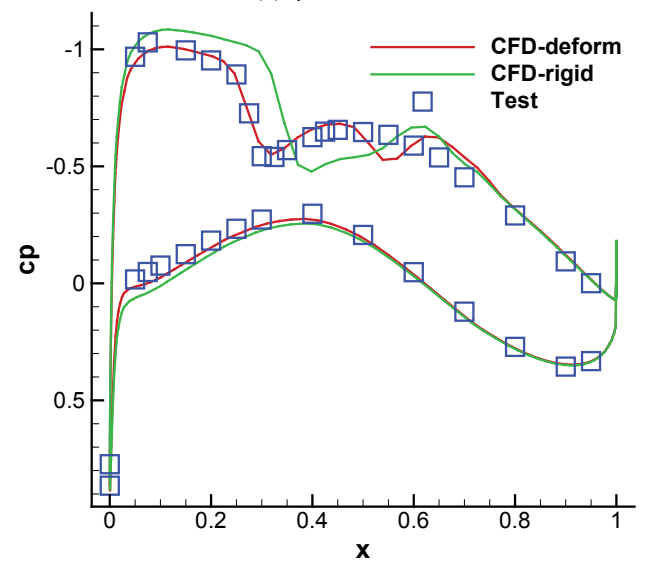

(b) $\eta=86.1 \%$

Figure 14 Comparison between experimental and numerical results of pressure coefficient for rigid and deformed models $\left(M=0.76, \alpha=2^{\circ}\right)$

\subsection{Correction of model deformation}

Correction of model deformation can be obtained by subtracting the numerical aerodynamic coefficients of original rigid model from those of deformed one. Then, corrected experimental data is obtained by subtracting the correction from original experimental results. This process could be described as the following formulas and the symbol $C x$ represents the longitudinal aerodynamic coefficients.

$$
\begin{aligned}
& \Delta C x_{\text {correction }}=C x_{C F D_{-} \text {deform }}-C x_{C F D \_r i g i d} \\
& \Delta C x_{\text {test_corrected }}=C x_{\text {test }}-C x_{\text {correction }}
\end{aligned}
$$

Fig. 15 illustrates the comparison of longitudinal aerodynamic coefficients for rigid and deformed models at flight Reynolds number condition. As one can see from Fig. 15, the lift coefficient $C_{L}$ of deformed model is smaller than that of rigid model at the same incidence angles. The $C_{L}$ differences of two models become larger with the increasing of incidence angles, suggesting the lift curve slope of deformed model decreases. It is obviously seen from Fig. 15 that a nose up pitching moment occurs after model deformation, while the drag coefficient of deformed model is smaller at positive incidence angles.

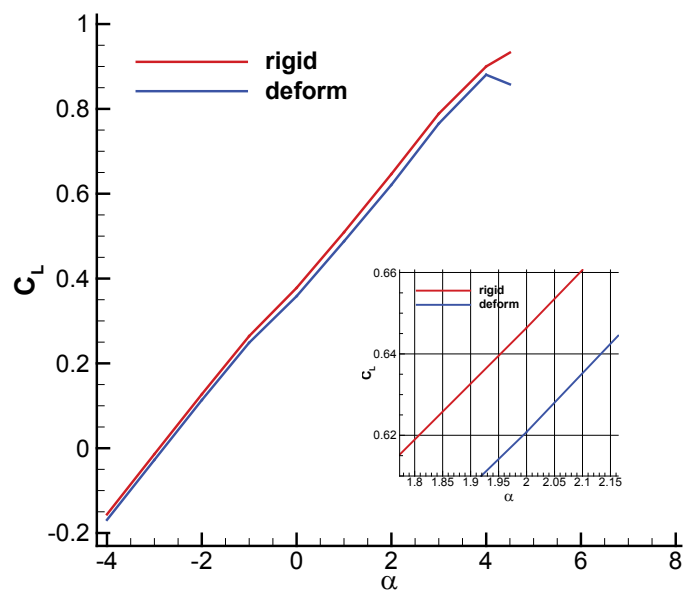

(a) $C_{L} \sim \alpha$

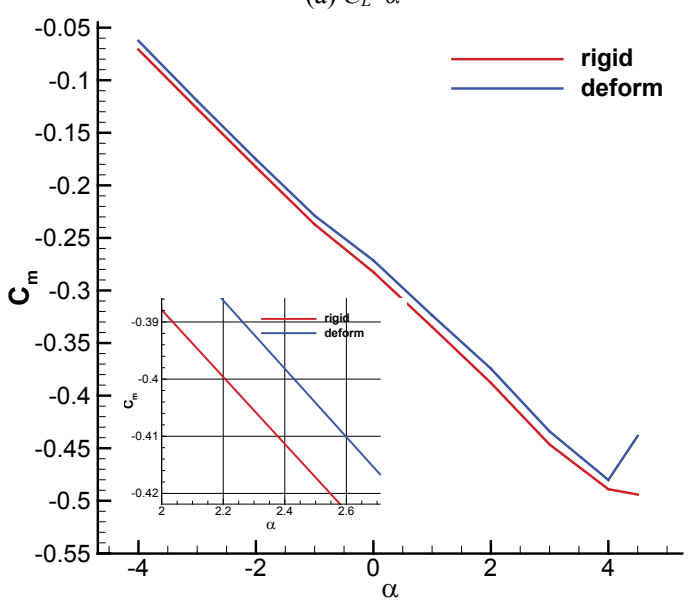

(b) $C_{m} \sim \alpha$

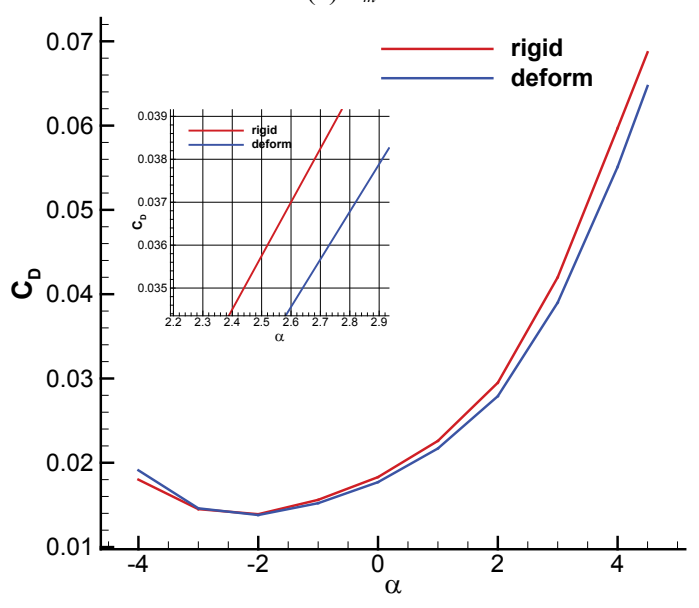

(c) $C_{D} \sim \alpha$

Figure 15 Longitudinal aerodynamic characteristic comparison of rigid and deformed models at $M=0.76, Q=92 \mathrm{kPa}$ and $R e=3.5 \times 10^{7}$

The model deformation influence mechanism of longitudinal aerodynamic coefficient is that local incidence angle decreases for each wing section. The lift of the wing section decreases while local incidence angle decreases, which results in the loss of whole lift integrated from all wing section. The lift loss mainly comes from 
trailing edge areas due to a smaller twist angle of deformed wing section. Therefore, considering the reference point of pitching moment is in front of trailing edge, the pitching moment of deformed model goes up. The model deformation effects of drag coefficient are complex. Lift loss is the main factor of the drag decreasing at the same incidence angle for deformed model.

Values of model deformation correction at different incidence angles are listed in Tab. 2 and Tab. 3 at different test conditions. The low Reynolds number test data could be corrected according to Tab. 2, while flight Reynolds number test data could be corrected according to Tab. 3 .

Table 2 Correction of longitudinal aerodynamics at different incidence angles $\left(M=0.76, Q=34 \mathrm{kPa}\right.$ and $\left.R e=3.3 \times 10^{6}\right)$

\begin{tabular}{|c|c|c|c|}
\hline$\alpha /^{\circ}$ & $\Delta C_{L}$ & $\Delta C_{D}$ & $\Delta C_{m}$ \\
\hline-4.0 & 0.0008 & -0.0001 & -0.0001 \\
\hline-3.0 & -0.0006 & -0.0002 & 0.0003 \\
\hline-2.0 & -0.0012 & -0.0001 & 0.0008 \\
\hline-1.0 & -0.0027 & 0.0001 & 0.0016 \\
\hline 0.0 & -0.0035 & -0.0001 & 0.0021 \\
\hline 1.0 & -0.0045 & -0.0001 & 0.0026 \\
\hline 2.0 & -0.0061 & -0.0001 & 0.0050 \\
\hline 3.0 & -0.0064 & -0.0009 & 0.0038 \\
\hline 4.0 & -0.0044 & -0.0013 & 0.0020 \\
\hline 4.5 & -0.0036 & -0.0014 & 0.0012 \\
\hline 5.0 & -0.0037 & -0.0013 & 0.0016 \\
\hline 6.0 & 0.0215 & -0.0006 & -0.0120 \\
\hline
\end{tabular}

Table 3 Correction of longitudinal aerodynamics at different incidence angles $\left(M=0.76, Q=92 \mathrm{kPa}\right.$ and $\left.R e=3.5 \times 10^{7}\right)$

\begin{tabular}{|c|c|c|c|}
\hline$\alpha /^{\circ}$ & $\Delta C_{L}$ & $\Delta C_{D}$ & $\Delta C_{m}$ \\
\hline-4.0 & -0.0130 & 0.0011 & 0.0084 \\
\hline-3.0 & -0.0136 & 0.0001 & 0.0074 \\
\hline-2.0 & -0.0138 & -0.0001 & 0.0074 \\
\hline-1.0 & -0.0155 & -0.0004 & 0.0083 \\
\hline 0.0 & -0.0197 & -0.0006 & 0.0111 \\
\hline 1.0 & -0.0214 & -0.0009 & 0.0111 \\
\hline 2.0 & -0.0256 & -0.0016 & 0.0136 \\
\hline 3.0 & -0.0235 & -0.0030 & 0.0125 \\
\hline 4.0 & -0.0196 & -0.0046 & 0.0088 \\
\hline 4.5 & -0.0748 & -0.0040 & 0.0558 \\
\hline
\end{tabular}

\section{Conclusion}

Deformation of the supercritical wing test model was measured by SPT system in ETW. The bending deformation is positive and twist deformation is minus at positive incidence angles and it is the reason why the loss of lift coefficient occurs and pitching moment goes up after model deformation due to the aerodynamic loading. Structure grids deformation technology developed in this paper is feasible and reliable. In this method, the grids topology and boundary layer mesh density of deformed model could be kept the same as those of original one, thus reducing the computational errors due to variation of mesh structure.

The numerical method developed to simulate the model deformation is proved to be reliable by the comparison of experimental and computational results. A good correlation of the pressure coefficient distribution of test and numerical results for deformed model has been achieved. The correction of supercritical wing model could be obtained by subtracting the computational longitudinal aerodynamic coefficients of original model from those of deformed model. The correction of model deformation could be used to correct the original wind tunnel data.

\section{Acknowledgement}

The authors would like to thank Matthias Schulz and other partners from ETW for performing the experiment, and for the description of STP system in this paper offered by them.

\section{References}

[1] Gibson, T. Investigation of Wind Tunnel Model Deformation under High Reynolds Number Aerodynamic Loading. // 40th AIAA Aerospace Sciences Meeting \& Exhibit, Aerospace Sciences Meetings, AIAA 2002-0424, 2002. https://doi.org/10.2514/6.2002-424

[2] Abdullah, T. A.; Petrović, Z.; Stefanović, Z.; Kostić, I.; Isaković, J. Two-dimensional wind tunnel measurement corrections by the singularity method. // Tehnicki vjesnikTechnical Gazette. 22, 3(2015), pp. 557-565. https://doi.org/10.17559/TV-20140214114718

[3] Dawei Liu, Dehua Chen, Qiang Li. Investigation on the correlation of CFD and EFD results for a supercritical wing. // International Journal of Heat and Technology. 33, 3(2015), pp. 19-26. https://doi.org/10.18280/ijht.330303

[4] Germain, Eric; Quest, Jurgen. The Development and Application of Optical Measurement Techniques for High Reynolds Number Testing in Cryogenic Environment. // AIAA paper. 2005-0458.

[5] Luo, Chuan; Zhang, Zhengyu. Exterior orientation for videogrammetric model deformation measurement. // Journal of Experiments in Fluid Mechanics. 24, 6(2010), pp. 88-91.

[6] Constantin, T. Motion picture stabilizing achieved by mechanical engineering: Shooting video using three axis camera gimbals. // Academic Journal of Manufacturing Engineering. 13, 3(2015), pp. 70-81.

[7] Vlad, B.; Marius, B.; Lucian, F. Components of FMEA database for the measurement process. // Academic Journal of Manufacturing Engineering. 13, 3(2015), pp. 12-17.

[8] Burner, A. W.; Fleming, G. A.; Hoppe, J. C. Comparison of three optical methods for measuring model deformation. // AIAA 2000-0835, 2000.

[9] Liu, T.; Cattafesta, L. N.; Radeztsky, R. H.; Burner, A. W. Photogrammetry applied to wind tunnel testing. // AIAA Journal. 38, 6(2000), pp. 964-971. https://doi.org/10.2514/2.1079

[10] Song, Jin; Ma, Jun; Jiang, Min. Application research of Optotrak system in model deformation and attitude measurement in wind tunnel. // Transducer and Microsystem Technologies. 30, 12(2011), pp. 65-67.

[11] Sun, Yan; Deng, Xiaogang; Zhang, Zhengyu. Target influence on video model deformation experiments in transonic wind tunnel. // Acta Aerodynamica Sinica. 31, 6(2013), pp. 769-775.

[12] Schulz, Matthias; Quest, Juergen. New Techniques for Operation in Cryogenic Windtunnel. // AIAA 2007-749, 2007.

[13] Ansell, D. M.; Schimanski, D. Non-intrusive optical measuring techniques operated in cryogenic test conditions at the European Transonic Windtunnel. // AIAA 99-0946, 1999.

[14] Burner, A. W.; Goad, W. K. Wing Deformation Measurements of the DLR-F6 Transport Configuration in the National Transonic Facility. // AIAA 2008-6921, 2008. 
[15] Jianmin, Xu; Shuiting, Zhou; Kunsheng, Li. Analysis of flow field and pressure loss for fork truck muffler based on the finite volume method. // International Journal of Heat and Technology. 33, 3(2015), pp. 85-90. https://doi.org/10.18280/ijht.330312

[16] Hong, Yin; Dong, Sun; Xingyuan, Li. Airflow simulation of linear grating lithography workshop. // International Journal of Heat and Technology. 33, 2(2015), pp. 109-114. https://doi.org/10.18280/ijht.330218

[17] Oumrani, N.; Aouissi, M.; Bounif, A. A first-and secondorder turbulence models in hydrogen non-premixed flame. // International Journal of Heat and Technology. 33, 3(2015), pp. 27-34. https://doi.org/10.18280/ijht.330304

[18] Cundong, Xu; Hongyang, Zhang; Xianqi, Zhang. Numerical simulation of the impact of unit commitment optimization and divergence angle on the flow pattern of forebay. // International Journal of Heat and Technology. 33, 2(2015), pp. 91-96. https://doi.org/10.18280/ijht.330215

[19] Li, S.; Liu, D. W.; Li, Q. The optimal design of a wind tunnel model sting system based on the CFD method. // International Journal of Heat and Technology. 33, 4(2015), pp. 137-144. https://doi.org/10.18280/ijht.330417

[20] Cui, W. Z.; Zhang, X. T.; Li, Z. X.; Li, H.; Liu Y. Threedimensional numerical simulation of flow around combined pier based on detached eddy simulation at high Reynolds numbers. // International Journal of Heat and Technology. 35, 1(2017), pp. 91-96. https://doi.org/10.18280/ijht.350112

[21] Petrovic, I.; Kosel, F.; V. Sajn. Aerodynamic investigation of the deformable membrane airfoil with excess length. // Tehnicki vjesnik-Technical Gazette. 22, 3(2015), pp. 573580. https://doi.org/10.17559/TV-20131210105304

[22] Sun, Yan; Zhang, Zhengyu; Deng, Xiaogang. Static aeroelastic effects of wind tunnel model on aerodynamic forces. // Acta Aerodynamica Sinica. 31, 3(2013), pp. 294300.

\section{Authors' addresses}

Dawei Liu, PhD Candidate

Xin Xu, PhD Candidate

Qiang Li, Engineer

Xin Peng, Assistant Professor

Dehua Chen, PhD Professor

State Key Laboratory of Aerodynamics

Mailbox 101, Beichuan, Mianyang city,

Sichuan province, PRC, 621000

E-mail: liudawei@mail.ustc.edu.cn 